\title{
Advanced Prostate Cancer: A Case Report
}

\author{
A. S. Ondziel Opara, A. M. Ondongo Atipo, A. W. S. Odzébé*, R. B. Banga Mouss, B. Lebweze, \\ P. A. Bouya
}

Service d'urologie-andrologie, CHU de Brazzaville, Brazzaville, Congo

Email: *odzebe_s@yahoo.fr

How to cite this paper: Ondziel Opara, A.S., Ondongo Atipo, A.M., Odzébé, A.W.S., Banga Mouss, R.B., Lebweze, B. and Bouya, P.A. (2019) Advanced Prostate Cancer: A Case Report. Open Journal of Urology, 9, 11-18.

https://doi.org/10.4236/oju.2019.91002

Received: October 3, 2018

Accepted: January 14, 2019

Published: January 17, 2019

Copyright (c) 2019 by author(s) and Scientific Research Publishing Inc. This work is licensed under the Creative Commons Attribution International License (CC BY 4.0).

http://creativecommons.org/licenses/by/4.0/

\begin{abstract}
There are few reported cases in the prostate adenocarcinoma literature with locoregional extension and normal prostate-specific antigen (PSA). We present the case of a patient with prostate adenocarcinoma and metastases with PSA values within the normal range, despite evidence of clinical and radiological progression of the disease. This is a 72-year-old patient presenting with a dysectatic syndrome in which there is a budding ulceration of the glans, an induration of the corpora cavernosa and whose rectal examination has objectified a malignant prostate. PSA was assayed at $3.47 \mathrm{ng} / \mathrm{ml}$; prostatic biopsy and magnetic resonance imaging (MRI) revealed prostate cancer with extension to the urethral, cavernous and rectal areas. Hormone therapy was instituted and the course after two months was marked by the occurrence of several episodes of anemia treated by blood transfusion.
\end{abstract}

\section{Keywords}

Prostatic Adenocarcinoma, Penile, Urethra, Rectum

\section{Introduction}

Prostate cancer is the most common cancer in male gender. It represents the third leading cause of cancer mortality among men over 50 years in France and Europe. Since 2005, its incidence has been constantly increasing due to a more targeted practice of screening and improvement of diagnostic tools. Early individual diagnosis is based on an assay of the PSA rate associated with digital rectal examination, annually, in men aged from 50 to 75 years with a life expectancy of more than 10 years [1].

However, more recent studies have shown that some men with PSA levels below $4.0 \mathrm{ng} / \mathrm{ml}$ have prostate cancer and others with higher levels do not [2]. Although normal PSA values in the presence of prostate cancer are considered rare, in the literature this has been described as occurring in about $20 \%$ of cases. 
Nevertheless, this situation is generally rare in cases of extensive metastatic disease [3].

We present the case of a patient with adenocarcinoma of the prostate with an extension at the corpus cavernosum, bulbar urethra, membranaceous urethra and rectum whose PSA values are within the limit of normal, despite evidence of clinical and radiological progression of the disease.

\section{Case Report}

A 72-year-old man was admitted on January 29, 2018 in the urology department of the University Hospital of Brazzaville for a total hematuria associated with a rectorragie and a deterioration of the general state. This symptomatology was preceded by a dysectatic syndrome characterized by dysuria with a delayed onset and a nocturia made up of four nocturnal lifts. This symptomatology has been evolving for 2 years. He is married, father of 3 children, with a personal history of ischemic heart disease of blood hypertension origin treated with acetyl salicylic acid at a dose of 100 miligram (mg) per day, and vastatine at a rate of one tablet per day, and $10 \mathrm{mg}$ amlodipine daily. In his family history there is a notion of breast cancer in her mother and prostate cancer in two of his brothers.

- The clinical examination made it possible to objectify:

Budding ulceration about 1 centimetru $(\mathrm{cm})$ in diameter at the balano-preputial sulcus (Figure 1) and induration of the cavernous body.

At the rectal examination, the presence of a prostate enlarged volume, hard consistency, irregular surface with erasure of the median furrow, painless. The fingerstall returns stained with blood.

Initial management consisted of the placement of a dual-current charriere $(\mathrm{CH}) 22$ urethro-vesical catheter with bladder irrigation system in place. The evolution is marked by the complete remission of hematuria.

- Paraclinical assessment:

Two PSA Total dosages in one week at the same laboratory are 7.4 and 3.47 nanogram per militru $(\mathrm{ng} / \mathrm{ml})$, respectively.

The serum creatinine level is $9.3 \mathrm{mg} / \mathrm{l}$.

The dosage of uremia is $0.26 \mathrm{~g} / \mathrm{L}$.

A cytobacteriological examination of the urine has reported the presence of Escherichia coli (E. coli). Levofloxacin-sensitive E. coli administered at a dose of

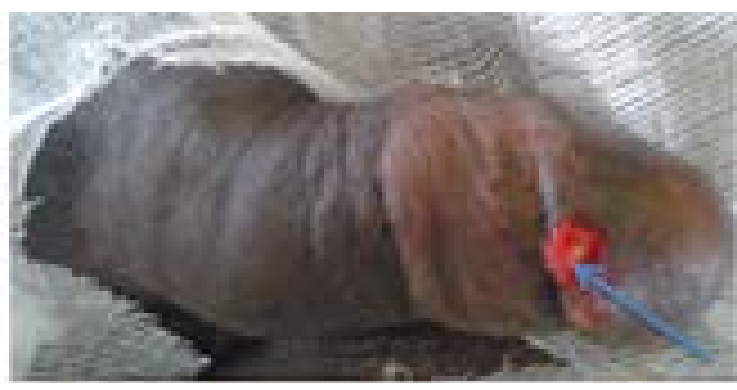

Figure 1. Budding ulceration at the balano-preputial furrow (blue arrow). 
$500 \mathrm{mg}$ once a day.

A recto-sigmoidoscopy showing congenital anorectal mucosa, a 6-hour ulcer bleeding rectal lesion on contact, and bleeding from the upper gastrointestinal tract. The indication of total colonoscopy was required to explore this bleeding.

Ultrasound of the urinary shaft shows a prostatic hypertrophy of $107.36 \mathrm{~g}$.

An exit was decided with the continuation of the biological investigation and imaging outpatient report, as well as a consultation in gastroenterology.

Five days after discharge, the patient experienced diffuse pain in the penis, urethrorrhagia, bladder retention of urine by clot, deterioration of general condition with resumption of rectorrhagia, and anemia, again justifying his admission to the service.

The management consisted of the placement of a cystostomy tube containing turbid urines, a compressive bandage of the penis, and paracetamol at a rate of 3 grams per day in 3 doses.

- Paraclinical assessment:

- The blood count, the hemoglobin level was $7.6 \mathrm{~g} / \mathrm{dl}$.

- Urethrocystoscopy had shown a bleeding urethral tumor in contact extending from the bulbar urethra to the prostate.

- Prostate MRI revealed a large prostatic tumor process, irregular, heterogeneous, poorly limited contours invading the anorectal region behind, cavernous body (Figure 2; Figure 3).

- Prostatic biopsy with anatomo-cyto-pathological analysis in favor of a prostate adenocarcinoma with a probable Gleason score of $5+5=10$ (Figures 4-6).

The diagnosis of prostate cancer with an extension of the corpus cavernosum, urethra and rectum associated with rectorrhagia was retained. It has been classified T4N0MX.

Hormonal therapy with $200 \mathrm{mg}$ of ciproterone acetate in 2 doses, triptorelin $3.75 \mathrm{mg}$ every 28 days, and iron supplementation were prescribed.

The evolution at the end of two months is marked by the occurrence of repeated anemias requiring several transfusions with erythrocyte pellets, then the patient's death.

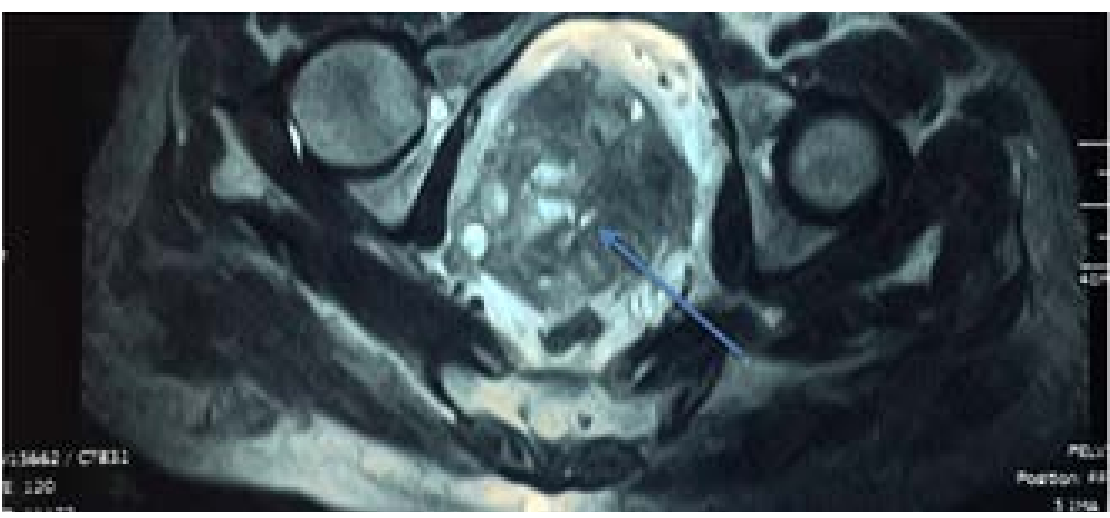

Figure 2. MRI bulky prostatic tumor process, irregular contours, heterogeneous, poorly limited (blue arrow). 


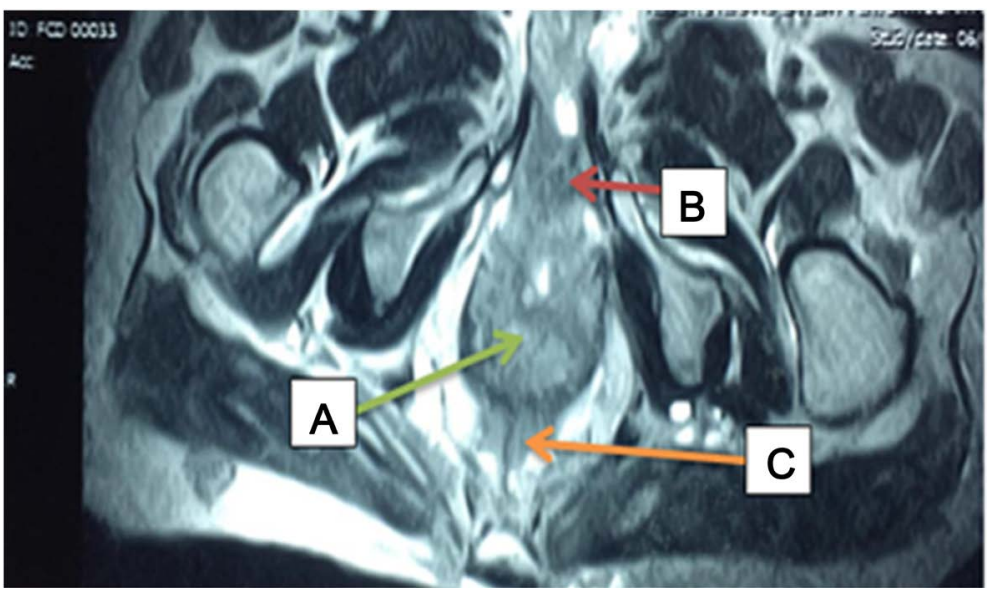

Figure 3. Prostatic tumor process $(\mathrm{A})$ invading the anorectal region behind $(\mathrm{C})$, cavernous body (B).

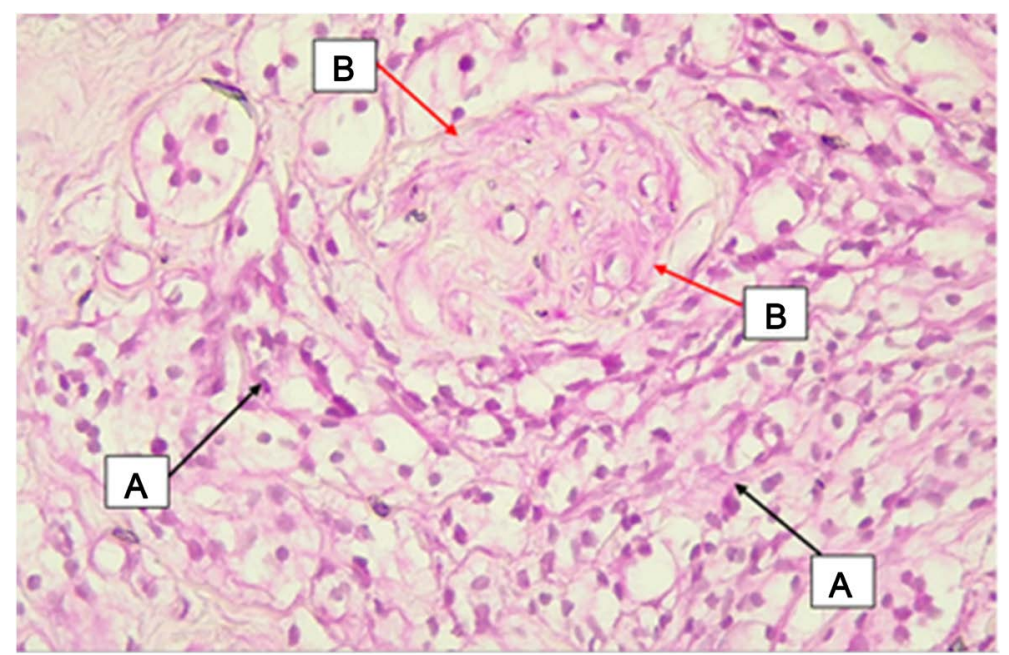

Figure 4. Grade 5 prostate carcinoma (histopronostic score $5+5=10$ ) $\times 40$, because compact aspect (B) and peri-nervous training (A).

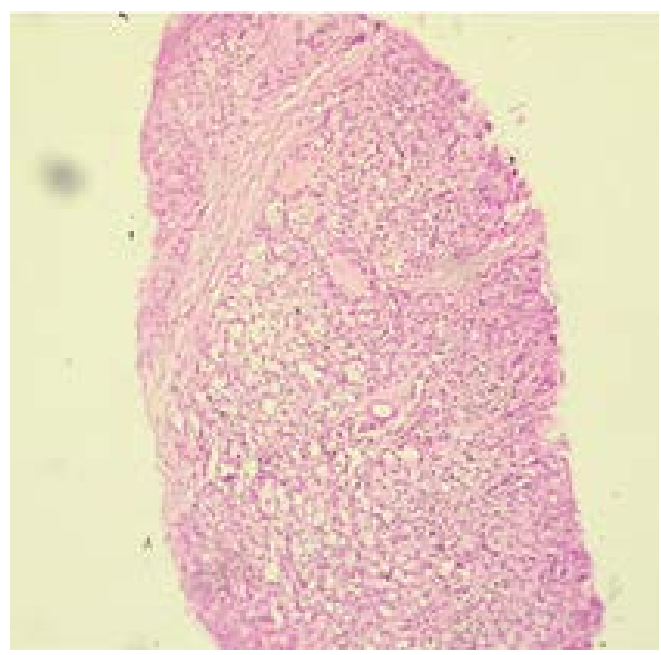

Figure 5. Grade 5 prostate carcinoma (score $5+5=10$ ) $\times 10$ predominant compact pattern. 


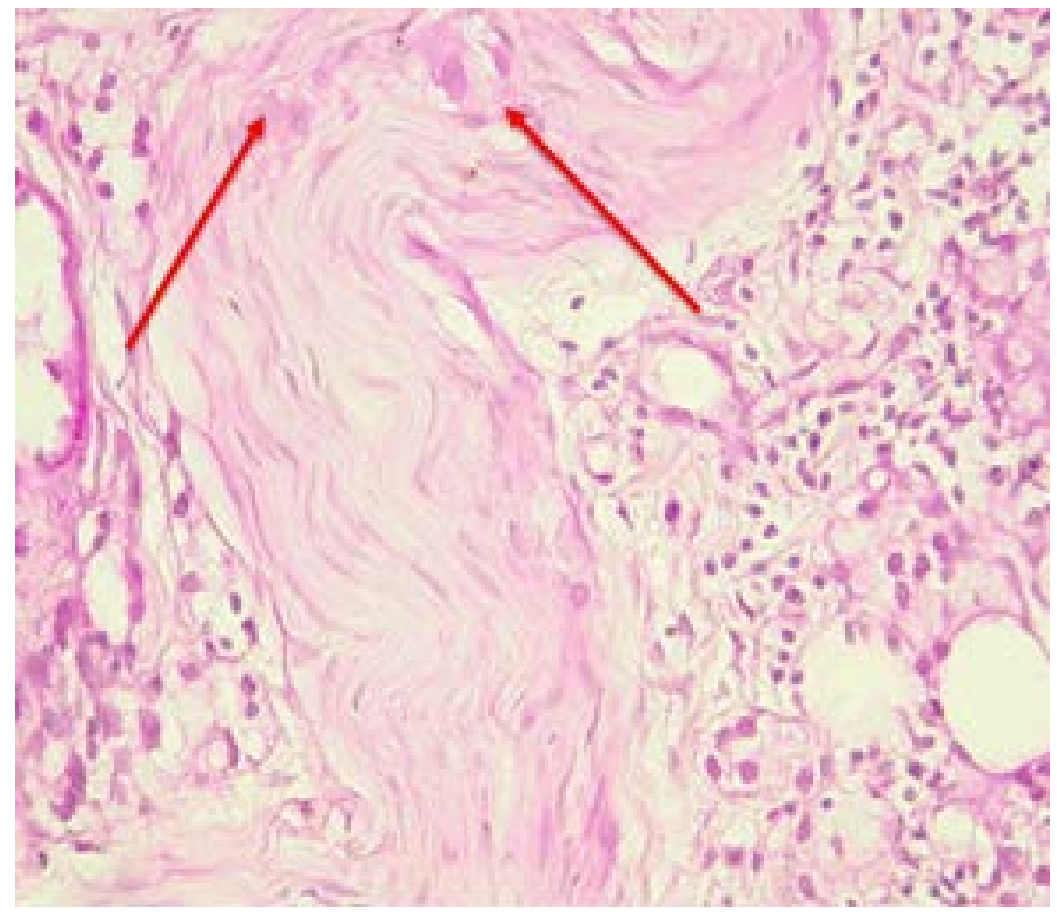

Figure 6. Grade 5 prostate carcinoma (score $5+5=10) \times 40$. There are perinervous muscles (red arrow).

\section{Discussion}

Prostate cancer is common in men over 50 [4]. Changes in the patient's lifestyle, diet and environment, as well as improved early detection, have increased the incidence [5]. Prostate cancer can spread through the lymph and blood vessels, or by direct extension to nearby organs. PSA, which is a glycoprotein produced almost exclusively by the epithelial component of the prostate, is a marker of the prostate. It may not be expressed in all patients with prostatic adenocarcinoma [6], the most commonly encountered histopathological form [7]. In addition, the development of metastatic prostate cancer producing undetectable or low serum PSA levels is not uncommon [8]. Having a patient with a PSA at $3.47 \mathrm{ng} / \mathrm{ml}$ and an extension at the level of the cavernous body, the urethra and the rectum by a very painful ulcero-budding rectal lesion, as in our case, raises questions. on the origin of the primary tumor. Would it be a primary prostate cancer or a cancer with urethral or rectal origin or would it be three totally independent tumors?

Although a protective role of Denonvilliers fascia is recognized against tumor extension from the prostate to the rectum [9], its extension to colorectal tissue, though rare, can occur in at least 3 potential pathways. The first is that of its direct extension through the fascia of Denonvilliers and infiltration of the rectum. The second is that through the lymphatic vessels, since the prostate and rectum receive in common some pelvic lymph nodes [10]. The third is where prostate cancer cells can spread through the biopsy needle, sowing in perirectal or rectal tissue; this route remains extremely rare [11] [12]. The incidence of rectal infiltration by prostatic adenocarcinoma is not common [13]. Yet we cannot exclude 
that it is a prostatic extension of a primary tumor from the colon. Bleeding of the upper gastrointestinal tract objectified during recto-sigmoidoscopy, would be an argument in favor of this insertion and also the colonoscopy that could have confirmed the diagnosis, could not be achieved because of the deterioration of the general condition of the patient. Bowrey et al. [13], in their study, found rectal infiltration by adenocarcinoma of the prostate, in one patient every two years while in our current practice, this eventuality is almost non-existent. Moreover, unlike our case, no history of prostate biopsy had been found.

Regarding the hypothesis about the possibility of primary urethral carcinoma, this possibility is also unlikely because of the clinical course of prostate cancer in this patient, cystoscopy results showing its locoregional extension.

The presence of ulceration at the level of the balano-preputial groove, leads us to distinguish the real penile metastases from a prostate adenocarcinoma that are very rare, and the infiltration of the penis by contiguity. The most typical often occur in the glans, in the form of very painful erythematous nodules. The diffusion is most often by lymphatic or venous retrograde. The extreme pain of these metastases of the glans can lead to discuss the penectomy. The prognosis is dramatic, with survivals generally exceeding one year only [14]. In view of all the above, this case described, corresponds to an extension of a prostate adenocarcinoma to neighboring organs.

In the literature, several authors [10] [11] [12] [13] [15] have detected certainly rare but isolated urethral, penile or rectal disorders by extension of an adenocarcinoma of the prostate. However, the case of a concomitant involvement of the urethra, penis and rectum with, in addition, a PSA within the limits of the normal, is exceptional

Given the tumor stage, the patient's treatment options are focused on palliative care because of his poor prognosis and the advanced nature of his disease. Complete androgenic blockade was prescribed. It combines an anti-androgen with a luteinizing hormone-releasing hormone (LHRH) antagonist. Regarding surgery, it also keeps its place especially for palliative indications in the framework of a urethral disobstruction or a urinary diversion or a total penectomy for extension in the cavernous body [16]. A urinary diversion was performed, it was a suprapubic cystostomy. Due to the deterioration of the general condition by bleeding and repeated anemia, significant risks associated with this surgery, the patient's clinical presentation and his desire not to have to undergo other invasive treatments, have led the medical team to limit itself to excluding total penectomy. Palliative external radiotherapy could have been another therapeutic option because of the lack of a technical platform; it was not possible to indicate this therapeutic modality.

\section{Conclusion}

Prostate cancer remains the most common cancer of men over 50 years. Adenocarcinoma is the most common histopathological form. The presence of a PSA 
level within normal limits does not exclude the existence not only of a prostate cancer but also of a cancer at a metastatic stage. This is why even in the presence of normal PSA, it is necessary to perform a prostate biopsy if the digital rectal examination is abnormal. The penis, the urethra and the rectum are areas where, of course, we rarely encounter metastases of prostatic adenocarcinoma, but they should not be ignored.

\section{Consent Chief of This Journal}

Written informed consent was obtained from one of the adult children for publication of this case report. A copy of the written consent is available.

\section{Acknowledgements}

We thank Professor LEBWEZE (Pathology) for his assistance with the case.

\section{Conflicts of Interest}

The authors declare no conflicts of interest regarding the publication of this paper.

\section{References}

[1] Terrier, M., Terrier, E., Paparel, N., Morel-Journel, Baldini, A., et al. (2017) Epidemiology, Diagnosis and Prognosis of Prostate Cancer. MedecineNucléaire, 41, 329-334.

[2] https://www.cancer.gov/types/prostate/psa-fact-sheet

[3] Ruiz-Martín, I., Rodríguez-Sánchez, C.A., Ocaña-Fernández, A., del Valle-Zapico, J., et al. (2005) Metastatic Prostate Cancer with a Normal Prostate-Specific Antigen Level. Clinical and Translational Oncology, 7, 412-413. https://doi.org/10.1007/BF02716588

[4] Kessler, E.R. and Flaig, T.W. (2014) Geriatric Considerations in the Treatment of Advanced Prostate Cancer. F1000Prime Reports, 6, 33.

[5] Antczak, A., Kluźniak, W., Wokolorczyk, D., Kashyap, A., Jakubowska, A., Gronwald, J., Huzarski, T., Byrski, T., Dębniak, T. and Masojć, B. (2013) A Common Nonsense Mutation of the BLM Gene and Prostate Cancer Risk and Survival. Gene, 532, 173-176. https://doi.org/10.1016/j.gene.2013.09.079

[6] Abbas, T.O., Al-Naimi, A.R., Yakoob, R.A., Al-Bozom, I.A., et al. (2011) Prostate Cancer Metastases to the Rectum: A Case Report. World Journal of Surgical Oncology, 9, 56. https://doi.org/10.1186/1477-7819-9-56

[7] Cortesi, M., Fridman, E., Volkov, A., Shilstein, S.Sh., Chechik, R., Breskin, A., Vartsky, D., Raviv, G. and Ramon, J. (2010) New Prospective for Non-Invasive Detection, Grading, Size Evaluation and Tumor Location of Prostate Cancer. Prostate, 70, 1701-1708. https://doi.org/10.1002/pros.21205

[8] Lee, D.K., Park, J.H. and Kim, J.H. (2010) Progression of Prostate Cancer Despite an Extremely Low Serum Level of Prostate-Specific Antigen. Korean Journal of Urology, 51, 358-361. https://doi.org/10.4111/kju.2010.51.5.358

[9] McLaughlin, P.W., Troyer, S., Sally Berri, B.S., Narayana, V., et al. (2005) Functional Anatomy of the Prostate: Implications for Treatment Planning. International Journal of Radiation Oncology, Biology, Physics, 63, 479-491. 
https://doi.org/10.1016/j.ijrobp.2005.02.036

[10] Murray, S.K., Breau, R.H., Guha, A.K. and Gupta, R. (2004) Spread of Prostate Carcinoma to the Perirectal Lymph Node Basin: Analysis of 112 Rectal Resections over a 10-Year Span for Primary Rectal Adenocarcinoma. American Journal of Surgical Pathology, 28, 1154-1162. https://doi.org/10.1097/01.pas.0000131543.80147.3d

[11] Vaghefi, H., Magi-Galluzzi, C. and Klein, E.A. (2005) Local Recurrence of Prostate Cancer in Rectal Submucosa after Transrectal Needle Biopsy and Radical Prostatectomy. Urology, 66, 881. https://doi.org/10.1016/j.urology.2005.04.005

[12] Lane, Z., Epstein, J.I., Ayub, S. and Netto, G.J. (2008) Prostatic Adenocarcinoma in Colorectal Biopsy: Clinical and Pathologic Features. Human Pathology, 39, 543-549. https://doi.org/10.1016/j.humpath.2007.08.011

[13] Bowrey, D.J., Otter, M.I. and Billings, P.J. (2003) Rectal Infiltration by Prostatic Adenocarcinoma: Report on Six Patients and Review of the Literature. Annals of the Royal College of Surgeons of England, 85, 382-385. https://doi.org/10.1308/003588403322520726

[14] Lebret, T. and Méjean, A. (2008) Rare Locations of Metastases from Prostate Cancer. Progrès en Urologie, 18, S357-S364. https://doi.org/10.1016/S1166-7087(08)74567-6

[15] Zardawi, I. and Chong, P. (2016) Metastatic Prostate Cancer to the Urethra Masquerading as Urothelial Carcinoma. Urology Case Reports, 7, 33-36.

[16] Cuvillier, X., Donnaint, A., Rigot, J.M. and Mazeman, E. (1995) Report of a Case of Penile Metastasis. Review of the Literature. Progrès en Urologie, 5, 1009-1011. 